Document downloaded from:

http://hdl.handle.net/10251/58380

This paper must be cited as:

Moreno-Ramón, H.; Marqués-Mateu, A.; Ibañez Asensio, S. (2014). Significance of Soil Lightness Versus Physicochemical Soil Properties in Semiarid Areas. Arid Land Research and Management. 28(4):371-382. doi:10.1080/15324982.2014.882871.

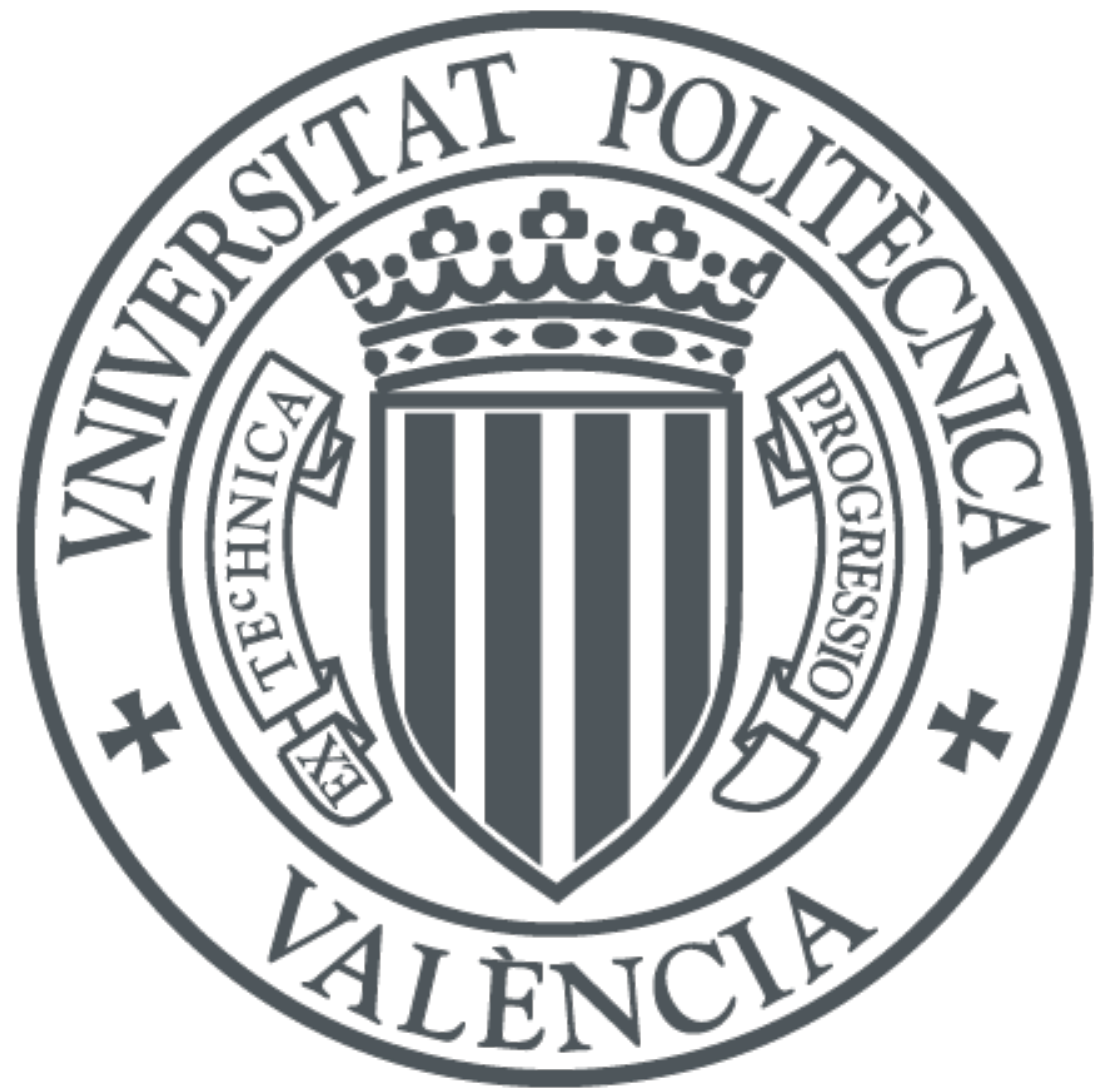

The final publication is available at

http://dx.doi.org/10.1080/15324982.2014.882871

Copyright Taylor \& Francis: STM, Behavioural Science and Public Health Titles

Additional Information

This is an author's accepted manuscript of an article published in " Arid Land Research and Management"; Volume 28, Issue 4, 2014; copyright Taylor \& Francis; available online at: http://www.tandfonline.com/doi/abs/10.1080/15324982.2014.882871 


\title{
The significance of soil lightness versus physicochemical soil properties in semiarid
} areas

\author{
Moreno-Ramón, H. ; Marqués-Mateu, A. ${ }^{\text {b; }}$ Ibáñez-Asensio, S.*a \\ ${ }^{a}$ Department of Plant Production, Universitat Politècnica de València, Camino de Vera s/n, \\ Valencia, 46022, Spain. \\ ${ }^{\mathrm{b}}$ Department of Cartographic Engineering, Geodesy and Photogrammetry, Universitat \\ Politècnica de València, Camino de Vera s/n, Valencia, 46022, Spain. \\ * Corresponding author. Tel.: +34963877333, Fax: +34963879749. \\ Camino de Vera s/n, Valencia, 46022, Spain. \\ E-mail address: sibanez@prv.upv.es
}

\section{Soil lightness and physicochemical soil properties}

\begin{abstract}
Modern agriculture aims to encompass all soil attributes to optimize soil use and minimize environmental impacts. One of those attributes is soil color, which allows determining important soil variables for crop management and soil conservation. In this study, the relationships between lightness and several pedologic, topographic and soil management variables were determined. One hundred and ten topsoil points were sampled in an area where the Mediterranean climate is the only homogeneous soil forming factor. Soil samples were air dried, crushed and sieved and lightness measurements were made using a trichromatic colorimeter. The relationships between lightness and soil-related parameters were carried out by means of bivariate linear correlation, and Mann-Witney and Kruskal-Wallis tests. Texture (sand and silt), electrical conductivity and carbonates were statistically significant $(\mathrm{P}<0.001)$ and exhibited moderate correlation coefficients (0.32-0.45). Topographic variables (slope and aspect), soil organic carbon, iron, nitrogen, $\mathrm{pH}$ and parent material (marls) exhibited lower effect on lightness. The response of lightness to clay content was highly conditioned by iron content. Stoniness, phosphorous, elevation and soil management variables (irrigation and land use) were not statistically significant. The results obtained with calcareous samples from semiarid areas showed that soil lightness behavior agree with findings in developed soils, despite of the large differences in soil composition and the heterogeneity of the study area.
\end{abstract}

Keywords: Colorimeter, Mediterranean environments, Soil color 


\section{Introduction}

In the current knowledge society, it is important to have reliable and instant data to properly make decisions. Because of this, researchers and organizations are increasingly creating detailed databases of soil characteristics. Soil scientists routinely use maps of soil units, erosion, degradation, nutrient elements, and other soil properties (Pan et al. 2010).

Although current technologies provide procedures for accessing digital soil datasets, it should be noted that analytical techniques still remain costly, both in time and money. Therefore, many research initiatives have been carried out for developing faster and cheaper measurement procedures. Soil color determinations can be one of them. Color provides valuable information on the formation, constituent elements, and other properties of soil (Buol et al. 2011) and is used as a basic feature in the taxonomy (Soil Survey Staff 2010). Humus (black and greyish pigments), iron hydroxides (reddish pigments), and silicic acid, kaolinite and calcium carbonate (white and greyish pigments) influence the three primary color components (value, hue and chroma according to Munsell notation). Other soil components and properties do not show such a clear influence on color, but even so, they can be identified by color and spectral measurements, as shown in several studies (Bogrekci \& Lee 2005; Christensen et al. 2004; Schwertmann 1993; Simonson 1993).

Soil color is relatively easy to measure and does not require expensive analytical procedures. This has led many researchers to find empirical relationships between color and other soil properties (Singleton 1991; Doi et al. 2010; Duiker et al. 2003; Mouazen et al. 2007).

However, it is not common to locate areas with uniform environmental conditions, where soil color differences are exclusively due to the attribute under study, without influence from other soil forming factors. In this regard, some authors have conducted experiments on wide areas with considerable variation in soil characteristics (Ibarra-F et al. 1995; Konen et al. 2003). Nonetheless, there is a lack of previous research in arid and semiarid areas where soils are weakly developed so that their properties are strongly tied to parent material, have different chromogen substance contents to those of soils from humid areas, and natural conditions have been modified by human activities such as irrigation, terracing and fertilization.

The aim of this paper is to improve the understanding about the topographic, pedologic, and management related soil variables that affect soil lightness in a semiarid environment where forming factors are very specific and have high spatial variability. The results of this paper allow one to eliminate non-significant variables and concentrate future research efforts on 
studying more in depth the variables that affect topsoil lightness. Precision agriculture, remote sensing and soil conservation applications are potential uses of these findings

\section{Materials and methods}

The study area is located in the municipality of Sax, province of Alicante, Spain. Samples were collected from topsoil $(0-10 \mathrm{~cm})$, over an area of 3000 ha where the Mediterranean climate is the only homogeneous soil forming factor in the working area.

The aridity condition is defined by temperature and rainfall regimes. In our study area the average annual rainfall is $305 \mathrm{~mm}$ and the average air temperature is $14.8^{\circ} \mathrm{C}$. The evapotranspiration rate is $846 \mathrm{~mm}$.

The geomorphology is determined by the river Vinalopó, which defines gentle slopes in fluvial terraces, and steep slopes in higher mountain areas. Elevation above sea level ranges from $471 \mathrm{~m}$ in the urban area, up to $1000 \mathrm{~m}$ in the highest mountain. The vegetation is highly dependent on agricultural uses. The main crops are vineyards, olive trees and almond trees either in irrigated or rainfed systems. The natural vegetation consists of Aleppo pines (Pinus halepensis Mill.) and various species of Mediterranean scrub (Fig 1).

Geological materials are limestones and marls of the Cretaceous and Tertiary and Triassic clays on hillsides, and Quaternary alluvium in the drainage network area of river Vinalopó and its tributaries (Fig 1). Steep slopes are particularly prone to water erosion which in turn influences soil formation. Soils are grouped into Aridisols and Entisols (Soil Survey Staff 2010). Younger soils occur in alluvial areas and have good characteristics for crop development and conversely, poorly developed soils and rocky masses are located in elevated areas of limestone that are not useful for agricultural use.

Samples were prepared and analyzed according to standard analytical techniques described in the Soil Survey Laboratory Methods Manual (Soil Survey Staff 2004). The specific methodologies were: Calcium Carbonate (Bernard calcimeter method), pH, electrical conductivity ( $\mathrm{EC}_{1: 5}$ method), texture (Bouyoucos method), total nitrogen (Kjedhal method), total phosphorus (Olsen method), organic carbon (Walkley-Black method), and Iron content (Dithionite citrate method). The sample preparation was carried out in order to remove uncertainty effects in lightness measurements due to water content and particle size of the samples (Barrett 2002; Sánchez-Marañón et al. 2007; Torrent \& Barrón 1993). The air-dried, crushed and sieved samples were transferred into measurement containers taking up all the available space before luminance measurements were executed. Instrumental memory effects across measurements were eliminated by measuring each sample three times, shaking the 
container before repeating the measurements, and by making several measurements on the white reference target throughout laboratory sessions.

In order to avoid Munsell Soil Color Charts limitations we used a Konica Minolta CS-100A chroma meter which provides chromaticity coordinates $\mathrm{xy}$, and luminance values $\mathrm{Y}$ in the socalled CIE xyY space. The use of CIE color spaces in soil science is well documented in the literature (Torrent \& Barrón 1993; Viscarra et al. 2006).

The colorimetry setup consisted of a light booth with $45^{\circ} / 0^{\circ}$ geometry and visual field of two degrees. The light source was a D65 illuminant simulator as recommended by the CIE for color experiments (CIE 2004). The colorimeter was positioned $1.2 \mathrm{~m}$ apart from samples without additional accessories interfering the measuring field of view. Laboratory measurements provided chromaticity coordinates and luminance of both soil samples and the white reference target. Chromaticity coordinates were then transformed into tristimulus values $\mathrm{XYZ}$ using well-known formulae:

$\mathrm{X}=\mathrm{Y} \cdot(\mathrm{x} / \mathrm{y})$

$\mathrm{Y}=\mathrm{Y}$

Eq 1

$\mathrm{Z}=\mathrm{Y} \cdot(1-\mathrm{x}-\mathrm{y}) / \mathrm{y}$

Next, tristimulus values were converted into CIELAB coordinates L*a*b* (CIE 2004):
$\mathrm{L}^{*}=116 \cdot\left(\mathrm{Y} / \mathrm{Y}_{\mathrm{n}}\right)^{1 / 3}-16$
Eq 2
$\mathrm{a}^{*}=500 \cdot\left[\left(\mathrm{X} / \mathrm{X}_{\mathrm{n}}\right)^{1 / 3}-\left(\mathrm{Y} / \mathrm{Y}_{\mathrm{n}}\right)^{1 / 3}\right]$
Eq 3
$\mathrm{b}^{*}=200 \cdot\left[\left(\mathrm{Y} / \mathrm{Y}_{\mathrm{n}}\right)^{1 / 3}-\left(\mathrm{Z} / \mathrm{Z}_{\mathrm{n}}\right)^{1 / 3}\right]$
Eq 4

where $\mathrm{X}, \mathrm{Y}, \mathrm{Z}$ are the tristimulus values of the sample and $\mathrm{X}_{\mathrm{n}}, \mathrm{Y}_{\mathrm{n}}, \mathrm{Z}_{\mathrm{n}}$ refer to white reference target. The CIELAB coordinate of interest in this paper is lightness or $\mathrm{L}^{*}(\mathrm{Eq} 2)$.

The whole set of data, i.e. pedologic, geomorphologic, management variables and $\mathrm{L}^{*}$, was gathered using a Geographical Information System (GIS). The geographical locations of soil samples were collected with handheld GPS receivers, whereas land use, lithology and geomorphologic variables were collected from existing maps (Spanish National Mapping Series MTN50 at scale of 1:50,000). The GPS data resulted in a point map of soil samples. Once the spatial datasets were stored in the same reference system, sample locations could be plotted over existing maps or aerial images to capture spatially distributed variables from within the GIS environment (Fig. 1). The spatially distributed variables collected from the maps include elevation, slope, aspect, and lithologic material. The GIS framework also provides computing tools to perform geostatistical analyses (Webster \& Oliver 2007). We used the simple kriging algorithm to prepare several plots of soil and landscape characteristics. 
In order to find out relationships between lightness and the quantitative soil variables we used the bivariate correlation analysis. The qualitative variables, i.e. irrigation (yes/no), parent material (Quaternary, clay and gypsum, limestone, marl), and land use (fruit trees, vineyard, forestry, and abandoned filed), were incorporated in the statistical models as dummy variables (Draper \& Smith 1981). The other analyzed variables (aspect, elevation above sea, slope, calcium carbonate $\left(\mathrm{CaCO}_{3}\right), \mathrm{pH}, \mathrm{EC}_{1: 5}$, texture, stoniness, total nitrogen $(\mathrm{Nt})$, total phosphorus (Pt), soil organic carbon (SOC), iron and lightness) were processed as quantitative variables (Table 1). The numerical data were arranged in tables, which were joined to the point map by means of a predefined key identifier.

The statistical distributions of variables were checked using the Kolmogorov-Smirnov normality test. We also computed the Spearman correlation coefficients to relate lightness to other variables studied. In the particular case of categorical variables, we used the MannWhitney and Kruskal-Wallis tests.

\section{Results and discussion}

\section{Analytical characteristics}

The main analytical characteristics of soils can be seen in Table 1. In summary, topsoils were stony, with coarse texture. They showed light colors and the carbonate content was high, whereas they were poor in organic matter and several elements, namely iron, nitrogen, and phosphorus. Soils were not saline, although samples near the banks of river Vinalopó had a maximum $\mathrm{EC}_{1: 5}$ value of $2.7 \mathrm{dS} / \mathrm{m}$. Samples were collected from four areas with moderate slope (5-12\%) and northwest, southeast, and southwest orientations. The elevations of the sampled sites ranged from $480 \mathrm{~m}$ to $678 \mathrm{~m}$ above sea level. Areas above $700 \mathrm{~m}$ elevation have steep slopes and contain rock masses, and consequently were not sampled.

\section{Soil and landscape characteristics}

In this section we show several plots of soil forming factors (Fig 1) and other soil characteristics (Fig 2). The highest carbonate contents were found on marls, which were located in low elevation areas, whereas the lowest were located at higher elevations (north east; Quaternary materials). There was high variability in carbonate content (ranging from $6.9 \%$ to $92.9 \%$ ) within Quaternary material samples. In addition to lithologic material characteristics, land use and soil management practices determine to a large extent the content of salts, iron, organic matter and nitrogen. The highest values of electrical conductivity were found in irrigated fields next to the river, where Triassic marls were located. 
Conventional tillage is common practice in agricultural lands, which explain the spatial distribution of SOC. The highest contents of iron occurred in the area where vineyard crops prevail and iron fertilization is applied.

The uppermost contents of SOC were found in areas with higher elevation and steeper slope where forest species provide high amounts of litter, and cultivated fields have large amounts of weeds as a consequence of accessibility limitations for agricultural machinery. Although currently there are several fields under conservation tillage, in more than $90 \%$ of the territory, mulching is not commonly practiced and intensive plough facilitates organic matter oxidation. The lowest contents of SOC were found in vineyards and abandoned fields at lower elevation. With regard to Nt behavior, the highest values occurred in abandoned fields and forest areas in the north of the study area, regardless of the orientation, elevation, or slope. The presence of weeds (leguminous) increase plant residues, and organic matter decomposition slows down after tillage stops, in the abandoned fields,

Topography and lithologic material determine soil texture distribution. Fine-textured soils were found in valley bottoms or depressions. Coarse-textured sandy soils were typical of Quaternary material.

\section{Relationships between lightness and soil characteristics}

According to data in Table 2, we point out that samples with large carbonate content had higher lightness, which is evidence that lithologic material has strong influence on the properties of weakly developed soils. This same behavior has been previously documented by other authors in studies conducted on soils with low contents of $\mathrm{CaCO}_{3}$, either as a consequence of decarbonation processes (Sánchez-Marañón et al. 1997), or as a result of noncalcareous material weathering (Spielvogel et al. 2004). In general, soils showed coarse textures and low levels of organic carbon $(<1.6 \%)$ and, consequently, the presence of carbonates generated higher lightness values than in soils with finer textures and higher contents of organic matter (Gunal et al. 2008).

With regard to electrical conductivity, high values are associated to high salt contents, and salts precipitation determine the reflectance characteristics of soils in dry environments (AlMawahili et al. 1983; Karavanova et al. 2001). In basic soils with low organic matter, saline crusts are white and are basically composed of sodium and magnesium chlorides and sulphates (FAO, 1993).

Our results showed that lightness becomes higher as $\mathrm{EC}_{1: 5}$ increases. Although we did not find evidence of surface salt crusts at sampling time, electrical conductivity values recorded in 
some locations suggest that crust formation can occur during dry periods with high rates of evaporation. Salt crystal can be even of microscopic size and may remain mixed with other soil particles as a consequence of tillage. These facts are also consistent with the sample preparation process in the laboratory. Sample drying produces salt precipitation, and crushing breaks salt crystals in fragments smaller than $2 \mathrm{~mm}$.

It should be noted that irrigation in Sax municipality is carried out with low quality water, which contributes with significant salt contents. The analyses of soil properties in relation to $\mathrm{EC}_{1: 5}$ with the Mann-Whitney test showed that high values correspond to soils developed on marls $(\mathrm{P}=0.001)$, mainly in irrigated fields $(\mathrm{P}=0.039)$, regardless of crop and slope.

The bivariate correlations between lightness and texture are well in line with general trends in this field (Sánchez-Marañón et al. 2011; Spielvogel et al. 2004). The fine-textured soils possess higher specific surface area which increases reflectivity and gives inverse relationships between sand particle size and lightness $(\mathrm{P}<0.001)$, and positive relationships between silt particle size and lightness $(\mathrm{P}<0.001)$. In our study, however, clay was not statistically significant but showed a slight negative trend (Table 2).

Several researchers found that, contrary to common belief, lightness values decrease when the number of clay sized particles increases, and they attribute their results to presence of free iron oxides (Sánchez-Marañón et al. 1997; Gunal et al. 2008). Iron oxides exhibit small particle size so that very small amounts suffice to affect soil color (Schwertmann, 1993) since some of those particles are retained on the negatively charged surface of clay grains. Our results are in concordance with their conclusions in those sites that contain higher amounts of iron. In general, the soils under study had low iron contents. However, if we look at areas with higher clay content (Fig 2) we can see that vineyards fields (subjected to chelated iron and iron sulphate fertilization) contain more Fe and show low $\mathrm{L}^{*}$ values. On the contrary, abandoned fields and almond tree orchards, exhibit the highest values of lightness. In any case, the relationship between iron oxide and soil lightness has been poorly documented in calcareous soils. Sánchez-Marañón et al. (1997; 2007) found contradictory results in several mediterranean areas, with different relationships between variables, depending on factors such as laboratory extractant or soil origin.

Iron and SOC have a combined influence on $\mathrm{L}^{*}$, and this effect is closely linked to the soil particle sizes. Schwertmann (1993) stated that soil color derived from iron oxides may be masked by humic matter and other oxides (Fe and Mn). Schulze et al. (1993) found that iron and SOC affect the spectral response of soils interacting with particle size. The statistical analysis used in this study cannot confirm those multivariate relationships, but outcomes point 
to this direction. It would be necessary to perform further analyses to check this issue. In the bivariate linear correlations we found that despite the low contents of these two chromogen components, the relationships were statistically significant. Finally, in relation to SOC effects on lightness, we obtained the same relationship found by others authors (Konen et al. 2003; Lindbo et al. 1998), but its significance was lower $(\mathrm{P}<0.05)$.

As for topographic characteristics, it is well accepted that in the northern hemisphere soils located on north oriented slopes receive less solar radiation than those located on south facing slopes (Geiger, 1950) which increases soil moisture and plant development. Therefore, north facing soils are expected to contain higher amounts of organic matter which produce darker colors. However, our results showed an opposite trend, that is, north oriented soils had lighter colors. This effect is caused by parent material, since soils are weakly developed and still retain many characteristics directly inherited from their parent material. White marl was the only geological material found on north oriented slopes, and consequently soil lightness increased. The influence of marl on lightness was confirmed by means of Mann-Whitney test $(\mathrm{P}=0.002)$. Regarding the other topographical variables, samples located on steepest slopes showed high lightness values due to the presence of marl and calcareous materials in those areas. On the contrary, elevation did not show influence on soil lightness.

Finally, management variables (land use and irrigation) did not show statistical significance on lightness $(\mathrm{P}=0.53$ and $\mathrm{P}=0.54)$. We point out that within land use factor, the different levels did not show significant differences in their effect on lightness, although forests and abandoned fields had higher SOC contents. The variables $\mathrm{N}$ and $\mathrm{P}$ showed little or no statistically significant influence on soil lightness, although there is some evidence of their relationships to color. Research in this field using UV and NIR sensors has undergone considerable development in the last years (Bogrekci \& Lee 2005; Christensen et al. 2004; Ehsani et al. 1999). Those studies are mainly oriented to improve fertilizer applications in site-specific agriculture, and to accomplish rapid determinations of mineral elements of soil. Our results from color measurements have proved to be inappropriate to explain relationships between soil lightness and those two variables. This can be attributed to the narrow spectral range of our instrument which is limited to the visible spectrum.

\section{Conclusions}

In the soils studied (Entisols and Aridisols), we found that soil lightness behaviour agree with results obtained in areas with different environmental characteristics. Pedologic properties were the most important variables related to soil lightness. In addition, experimental results 
showed that soil forming factors (topography and lithologic material) and management practices (land use, fertilization and tillage) determined those relationships. This fact is important in agricultural plots with heterogeneous characteristics caused by topography, anthropogenic processes or variability in parent materials, which are common in Spain and other Mediterranean countries. This heterogeneity in the study area led to weak or moderate correlation coefficients in the statistically significant variables.

Nitrogen and several chromogen substances such as soil organic carbon and iron have influence on $\mathrm{L}^{*}$ even when they are present in very limited amounts. The outcomes showed statistically significant influence similarly to that found in soils rich in those elements. The most specific properties of arid and semiarid areas, namely carbonates content and salinity, exhibited the highest influence.

It is confirmed that interactions between texture and iron exist. Experimental results showed a moderately negative relationship between soil lightness and sand, and a positive relationship between lightness and silt. The relationship between clay fraction and lightness was not statistically significant as a consequence of crop management (iron fertilization). We found both low values (vineyards) and high values of lightness (formerly cultivated lands and almond tree orchards) in soils with high clay contents.

\section{References}

Al-Mahawili, S. M. H., M.F. Baumgardner, R.A. Weismiller, and W.N. Melhorn. 1983. Satellite Image Interpretation and Laboratory Spectral Reflectance Measurements of Saline and Gypsiferous Soils of West Baghdad, Iraq. LARS Technical Reports. Paper 104.

Barrett, L.R. 2002. Spectrophotometric colour measurement in situ in well drained sandy soils. Geoderma 108: 49-77.

Bogrekci, I. and W.S. Lee. 2005. Spectral Phosphorus Mapping using Diffuse Reflectance of Soils and Grass. Biosystems Engineering 91: 305-312.

Buol, S.W., R.J. Southard, R.C. Graham, and P.A. McDaniel. 2011. Soil genesis and classification, 6th ed. John Wiley \& Sons, Chichester.

CIE. 2004. Colorimetry, Technical report. Commission Internationale de l'Éclairage, Vienna. Christensen, L.K., B.S. Bennedsen, R.N., Jorgensen, and H. Nielsen. 2004. Modelling nitrogen and phosphorous content at early growth Barley using Hyperspectral Line Scanning. Biosystems Engineering 88: 19-24. 
Doi, R., C. Wachrinrat, S. Teejuntuk, K. Sakurai, and P. Sahunalu. 2010. Semiquantitative colour profiling of soils over a land degradation gradient in Sakaerat, Thailand.

Environmental Monitoring Assessment 170: 301-309.

Draper, N., and H. Smith. 1981. Applied regression analysis. Wiley, New York.

Duiker, S.W., F.E. Rhoton, J. Torrent, N.E., Smeck and R. Lal. 2003 Iron hydroxide crystallinity effects on soil aggregation. Soil Science Society of America Journal 67: 606-611. Ehsani, M.R., S.K. Upadhyaya, D. Slaugther, S. Shafii, and M. Pelletier. 1999 A NIR Technique for Rapid Determination of Soil Mineral Nitrogen. Precision Agriculture 1: 217234.

FAO, 1993. Soil Tillage in Africa: needs and challenges. Food and Agriculture Organization Soils Bulletin no. 69. Soil Research. Management and Conservation Service. Rome. Geiger, R. 1950. The climate near the ground. Harvard University Press, Cambridge. Gunal, H., S. Ersahin., B. Yetgin and T. Kutlu. 2008. Use of chromameter-measured color parameters in estimating color-related soil variables. Communications in Soil Science and Plant Analysis 39: 726-740.

Ibarra-F, F.A., J.R. Cox, M.H. Martin-R, T.A. Crowl, D.F. Post, R.W. Miller, and G.A. Rasmussen. 1995. Relationships between Buffelgrass Survival, organic carbon and soil colour in Mexico. Soil Science Society of American Journal 59: 1120-1125.

Karavanova, E. I., D. P. Shrestha and D. S. Orlov. 2001. Application of remote sensing techniques for the study of soil salinity in semi-arid Uzbekistan. pp. 261-27, in W.M. Bridges, I.D. Hannam, L.R. Oldeman, F.W.T. Penning de Vries, S.J. Scherr, S. Sombatpanit, eds., Response to Land Degradation. Oxford \& IBH Publishing Co. Pvt. Ltd. New Delhi. India. Konen, M.E., C.L. Burras and J.A. Sandor. 2003. Organic carbon, texture and quantitative colour measurement relationships for cultivated soils in North Central Iowa. Soil Science Society of American Journal 67: 1823-1830.

Lindbo, D.L., M.C. Rabenhorst, and F.E. Rhoton. 1998. Soil color, organic carbon and hydromorphology relationships in sandy epipedons. pp. 95-105, in: M.C. Rabenhorst, J.C. Bell and P.A. McDaniel eds., Quantifying Soil Hydromorphology, Special Publication No. 54, Madison, WI.

Mouazen, A.M., M.R. Maleki, J. Baerdemaeker and H. Ramon. 2007. On-line measurement of some selected soil properties using a VIS-NIR sensor. Soil \& Tillage Research 93: 13-27. Pan., G, X. Xu, P. Smith, W. Pan and R. Lal. 2010. An increase in topsoil SOC stock of China's croplands between 1985 and 2006 revealed by soil monitoring. Agriculture, Ecosystems and Environment 136: 133-138. 
Sánchez-Marañón, M., G. Delgado, M. Melgosa, E. Hita and R. Delgado. 1997. CIELAB

Colour parameters and their relationships to soil characteristics in Mediterranean red soils. Soil Science 162: 833-842.

Sánchez-Marañón, M., M. Soriano, M. Melgosa, G. Delgado and R. Delgado. 2004.

Quantifying the effects of aggregation, particle size and components on the colour of Mediterranean soils. European Journal of Soil Science 55: 551-565.

Sánchez-Marañón M., R.B. Ortega, I. Miralles, and M. Soriano. 2007. Estimating the mass wetness of Spanish arid soils from lightness measurements. Geoderma 141: 397-406.

Sánchez-Marañón, M., J.M. Martín-García, and R. Delgado. 2011. Effects of the fabric on the relationship between aggregate stability and colour in a Regosol-Umbrisol soilscape.

Geoderma 162: 86-95.

Schulze, D.G., J.L. Nagel, G.E. Van Scoyoc, T.L. Henderson, M.F. Baumgardner, and D.E Stott. 1993. Significance of Organic Matter in Determining Soil Colors. pp. 71-90, in: J.M. Bigham and E.J. Ciolkosz, eds., Soil Color, SSSA Special Publication No 31 Soil Society of America, Madison.

Schwertmann, U. (1993) Relations between iron oxides, Soil colour and Soil formation, pp. 51-70, in: J.M. Bigham and E.J. Ciolkosz, eds., Soil Color, SSSA Special Publication No 31 Soil Society of America, Madison.

Simonson, R.W. 1993. Soil color standars and terms for field-use. History of their development. pp. 1-20, in: J.M. Bigham and E.J. Ciolkosz, eds., Soil Color, SSSA Special Publication No 31 Soil Society of America, Madison.

Singleton, P.L. 1991. Water table and soil colour as indicator of saturation in some soils of the Waikato, New Zealand. Australian Journal of Soil Research 29: 467-481.

Soil Survey Staff. 2004. Soil Survey Laboratory Methods Manual - Soil Survey Investigations Report No. 42. Version 4.0. Eds. Burt R. U.S. Department of Agriculture, Natural Resources Conservation Service, USA.

Soil Survey Staff. 2010. Keys to Soil Taxonomy, 11th ed. USDA-Natural Resources Conservation Service, Washington DC.

Spielvogel, S., H. Knicker, R.I. Kögel-Knabne. 2004. Soil organic matter composition and soil lightness, Journal of Plant and Nutrition and Soil Science 167: 545-555.

Torrent, J., and V, Barrón. 1993. Laboratory measurement of soil color: theory and practice. pp. 21-34, in: J.M. Bigham and E.J. Ciolkosz, eds., Soil Color, SSSA Special Publication No 31 Soil Society of America, Madison. 
Viscarra Rossel, R.A., B, Minasny, P. Roudier, and A.B. McBratney. 2006. Colour spaces for soil science. Geoderma 133: 320-377.

Webster, R., and M.A. Oliver. 2007. Geostatistics for Environmental Scientists, 2nd ed. John Wiley \& Sons, Chichester.

Table 1. Statistical summary of chemical and physical characteristics divided by parent materials.

\begin{tabular}{|c|c|c|c|c|c|c|c|c|c|c|c|c|c|c|c|c|}
\hline & & Stoniness & $\mathrm{pH}$ & $\mathrm{EC}_{1: 5}$ & $\mathrm{CaCO}_{3}$ & $\mathrm{Nt}$ & $\mathrm{Fe}$ & SOC & $\mathrm{Pt}$ & Clay & Silt & Sand & Elevation & Slope & Aspect & $\mathrm{L}^{*}$ \\
\hline & & $(\%)$ & & $\mathrm{dS} / \mathrm{m}$ & $\%$ & $\%$ & $(\%)$ & $\%$ & $\mathrm{mg} / \mathrm{Kg}$ & $\%$ & $\%$ & $\%$ & $\mathrm{~m}$ & $\%$ & o & $\begin{array}{l}\text { Cielab } \\
\text { Coord. }\end{array}$ \\
\hline \multirow{7}{*}{ 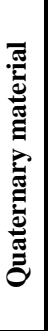 } & Mean & 41.4 & 8.3 & 0.5 & 29.6 & 0.1 & 0.5 & 1.0 & 0.5 & 15.2 & 23.6 & 61.2 & 541.5 & 3.5 & 225.7 & 56.2 \\
\hline & Median & 40.8 & 8.3 & 0.2 & 27.7 & 0.1 & 0.3 & 1.0 & 0.3 & 14.0 & 21.0 & 61.8 & 535.4 & 2.9 & 223.3 & 56.1 \\
\hline & Std. Dev. & 31.6 & 0.3 & 0.6 & 13.5 & 0.4 & 0.6 & 0.3 & 0.7 & 7.9 & 13.7 & 15.5 & 36.5 & 2.5 & 43.1 & 6.7 \\
\hline & C.V & 76.4 & 3.7 & 113.2 & 45.7 & 355.3 & 121.5 & 30.1 & 143.3 & 52.2 & 57.9 & 25.3 & 6.7 & 70.7 & 19.1 & 12.0 \\
\hline & Skewness & 0.3 & 0.6 & 2.2 & 1.1 & 0.8 & 1.8 & -0.1 & 2.9 & 0.9 & 1.3 & 348.0 & 1.0 & 2.1 & 0.4 & 0.1 \\
\hline & Maximum & 100.0 & 8.9 & 2.7 & 92.9 & 0.2 & 3.0 & 1.6 & 5.0 & 38.0 & 68.0 & 88.0 & 678.0 & 13.5 & 350.0 & 70.8 \\
\hline & Minimum & 0.1 & 7.4 & 0.2 & 6.9 & Ip & Ip & 0.2 & 0.1 & 3.0 & 2.0 & 20.0 & 479.5 & 0.6 & 96.7 & 42.1 \\
\hline \multirow{7}{*}{ 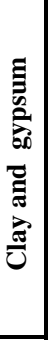 } & Mean & 28.3 & 8.2 & 0.9 & 22.8 & 0.1 & 0.7 & 1.1 & Ip & 16.7 & 34.3 & 49.0 & 508.0 & 1.8 & 236.4 & 53.7 \\
\hline & Median & 10.0 & 8.3 & 0.3 & 27.8 & 0.1 & 0.3 & 1.0 & Ip & 17.0 & 34.0 & 45.0 & 510.7 & 1.4 & 206.1 & 55.8 \\
\hline & Std. Dev. & 36.2 & 0.2 & 1.1 & 14.0 & 0.9 & 1.2 & 0.4 & Ip & 10.5 & 14.5 & 12.5 & 7.0 & 1.1 & 85.3 & 1.1 \\
\hline & C.V & 127.7 & 2.9 & 121.3 & 61.6 & 621.4 & 171.5 & 32.5 & Ip & 63.0 & 42.2 & 25.5 & 1.4 & 60.8 & 36.1 & 2.1 \\
\hline & Skewness & 1.5 & 1.6 & 1.7 & -1.4 & 1.6 & 1.7 & 1.7 & Ip & -0.1 & 0.1 & 1.3 & -1.5 & 1.3 & 1.4 & -0.8 \\
\hline & Maximum & 70.0 & 8.3 & 2.3 & 33.7 & 0.2 & 2.0 & 1.6 & Ip & 27.0 & 49.0 & 63.0 & 523.2 & 2.9 & 332.8 & 63.8 \\
\hline & Minimum & 5.0 & 7.9 & 0.3 & 26.7 & 0.1 & Ip & 0.9 & Ip & 6.0 & 20.0 & 39.0 & 500.1 & 0.9 & 170.3 & 41.6 \\
\hline \multirow{7}{*}{ 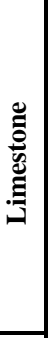 } & Mean & 50.0 & 8.6 & 1.0 & 40.9 & 0.1 & 0.3 & 0.6 & 1.2 & 14.3 & 40.0 & 45.7 & 618.7 & 3.0 & 228.4 & 59.8 \\
\hline & Median & 40.0 & 8.5 & 0.2 & 38.0 & 0.1 & 0.3 & 0.4 & 1.1 & 13.0 & 31.0 & 44.0 & 611.1 & 3.6 & 184.7 & 56.8 \\
\hline & Std. Dev. & 36.1 & 0.2 & 1.4 & 6.7 & 0.3 & 0.4 & 0.7 & 0.6 & 10.1 & 29.5 & 24.5 & 32.1 & 1.6 & 112.8 & 8.2 \\
\hline & C.V & 72.1 & 2.7 & 139.2 & 16.3 & 344.1 & 113.9 & 123.1 & 52.1 & 70.2 & 73.9 & 53.7 & 5.2 & 53.0 & 49.4 & 13.7 \\
\hline & Skewness & 1.2 & 1.7 & 1.7 & 1.6 & 1.5 & 0.9 & 1.2 & 0.8 & 0.6 & 1.2 & 0.3 & 1.0 & -1.5 & 1.5 & 1.4 \\
\hline & Maximum & 90.0 & 8.9 & 2.5 & 48.6 & 0.1 & 0.8 & 1.4 & 2.0 & 25.0 & 73.0 & 71.0 & 654.0 & 4.2 & 356.5 & 69.1 \\
\hline & Minimum & 20.0 & 8.5 & 0.2 & 36.2 & 0.1 & Ip & Ip & 1.0 & 5.0 & 16.0 & 22.0 & 591.1 & 1.2 & 144.0 & 53.6 \\
\hline \multirow{7}{*}{$\overline{\bar{\pi}}$} & Mean & 16.5 & 8.1 & 1.4 & 39.9 & 0.8 & 0.3 & 0.9 & 0.5 & 25.4 & 34.7 & 39.9 & 517.6 & 3.9 & 241.5 & 63.1 \\
\hline & Median & 7.5 & 7.9 & 1.8 & 45.7 & 0.1 & 0.3 & 0.9 & 0.3 & 29.0 & 36.0 & 32.0 & 508.4 & 3.0 & 238.6 & 62.0 \\
\hline & Std. Dev. & 17.6 & 0.3 & 1.0 & 17.5 & 0.0 & 0.3 & 0.4 & 0.5 & 14.6 & 15.1 & 19.8 & 38.3 & 3.1 & 44.1 & 4.6 \\
\hline & C.V & 1.1 & 4.1 & 71.4 & 44.0 & 3.8 & 99.3 & 47.5 & 97.9 & 57.6 & 43.4 & 49.5 & 7.4 & 78.5 & 18.3 & 7.4 \\
\hline & Skewness & 1.9 & 0.9 & -0.2 & -0.5 & 0.4 & 0.3 & -0.1 & 1.1 & 278.0 & -0.6 & 1.7 & 1.4 & 1.2 & 0.6 & 0.5 \\
\hline & Maximum & 60.0 & 8.7 & 2.4 & 60.1 & 0.4 & 0.9 & 1.6 & 1.0 & 43.0 & 60.0 & 87.0 & 600.0 & 10.3 & 323.1 & 71.3 \\
\hline & Minimum & 5.0 & 7.7 & 0.2 & 14.1 & 0.1 & Ip & 0.2 & 0.0 & 5.0 & 3.0 & 19.0 & 481.4 & 0.6 & 187.5 & 56.8 \\
\hline
\end{tabular}

$\mathrm{EC}_{1: 5}=$ Electrical conductivity ratio soil:water (1:5); $\mathrm{CaCO}_{3}=$ Carbonate content; $\mathrm{Nt}=$ Total nitrogen; $\mathrm{Fe}=\mathrm{Iron} ; \mathrm{SOC}=$ Soil organic carbon; $\mathrm{Pt}=$ Total phosphorus; $\mathrm{L}^{*}=$ Lightness; Ip=negligible. 
Table 2. Bivariate correlation between lightness and attributes investigated. $(* * \mathrm{P}<0.001$, * $\mathrm{P}<0.05)$

\begin{tabular}{|c|c|}
\hline Parameter & Spearman Coefficients \\
\hline $\mathbf{C a C O}_{3}$ & $0.45^{* *}$ \\
\hline $\mathbf{E C}_{1: 5}$ & $0.32^{* *}$ \\
\hline Sand & $-0.43^{* *}$ \\
\hline Silt & $0.45^{* *}$ \\
\hline Iron & $-0.24 * *$ \\
\hline SOC & $-0.22 *$ \\
\hline Aspect & $0.27 * *$ \\
\hline $\mathbf{p H}$ & $-0.19^{*}$ \\
\hline $\mathbf{N t}$ & $-0.19^{*}$ \\
\hline Slope & $0.20^{*}$ \\
\hline Clay & -0.02 \\
\hline Pt & 0.08 \\
\hline Stoniness & -0.044 \\
\hline Elevation & -0.13 \\
\hline
\end{tabular}



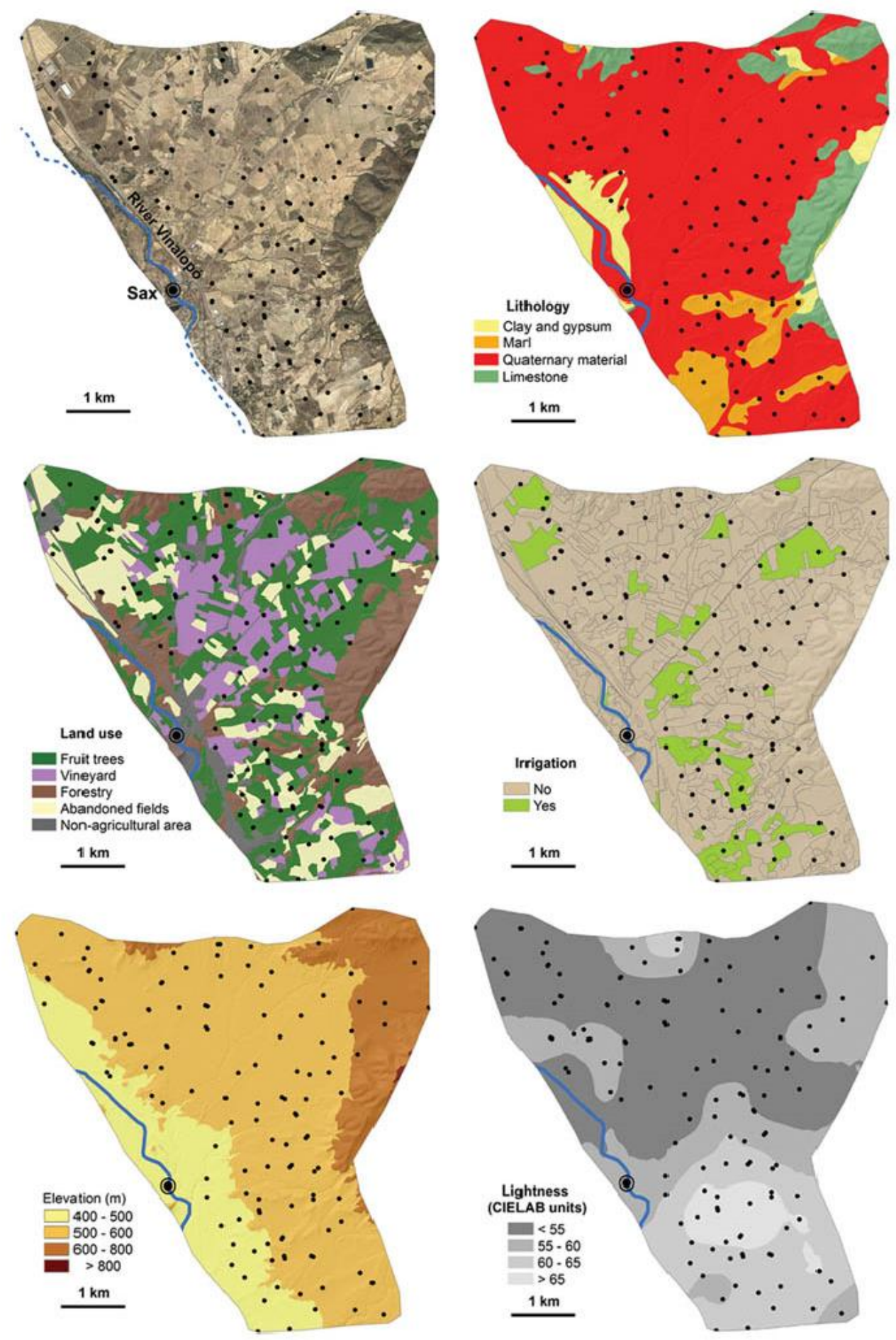

Figure 1. Landscape and management characteristics: orthophoto (top left), lithology (top right), land use (mid left), irrigation (mid right), elevation (bottom left), and lightness (bottom right). 


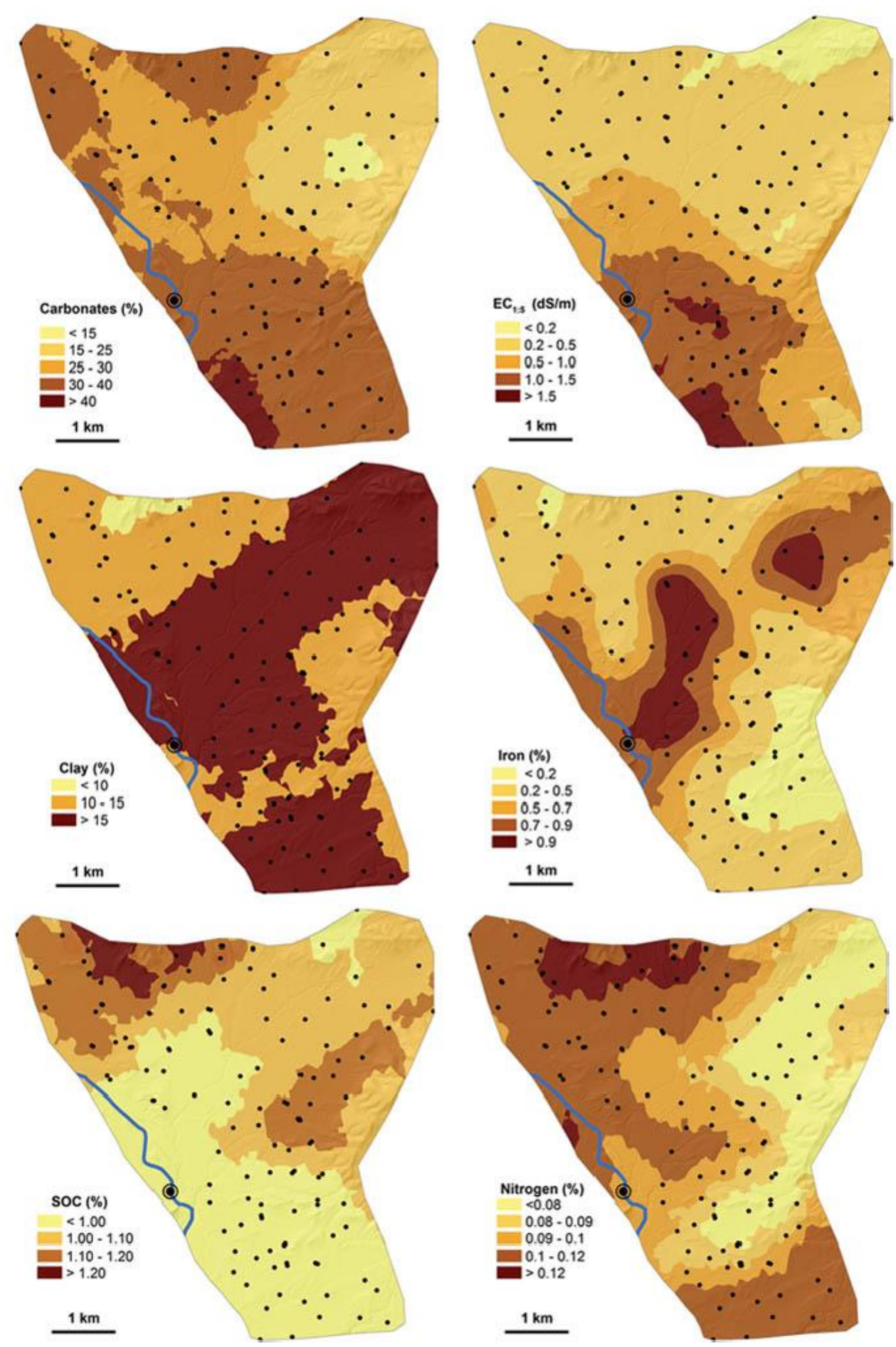

Figure 2. Soil characteristics: carbonates (top left), EC1:5 (top right), clay (mid left), iron (mid right), SOC (bottom left), and nitrogen (bottom right). 